\title{
IMS Learning Design 기반 e-PBL 프로토타입 개발 Development of e-PBL Prototype with IMS Learning Design
}

\author{
임철일", 홍성연*, 김선영* \\ 서울대학교 교육학과*, 아주대학교 기초교육대학** \\ Cheolil Lim(chlim@snu.ac.kr)*, Seongyoun Hong(hsy06@ajou.ac.kr)**, \\ Sunyoung Kim(ksystj@snu.ac.kr)*
}

\section{요약}

효과적인 e-PBL을 구현하기 위해서는 학습내용 중심이 아닌 학습활동 중심의 이러닝을 개발할 필요가 있다. 본 연구는 IMS Learning Design(IMS LD) 기반 e-PBL 프로토타입을 개발함으로써 학습활동 중심 의 이러닝의 구현 가능성에 대해서 살펴보았다. IMS LD 기반 e-PBL 프로토타입은 일반적인 이러닝 프로 그램과 비교하여 학습내용과 학습활동을 통합적으로 제시함으로써 적극적인 학습활동 참여를 유도하고, 학습자의 수준이나 학습자의 역할에 따라 서로 다른 학습내용 및 학습활동을 제공함으로써 적응적인 이러 닝 구현을 가능하게 하였다. 또한, 학습자의 학습활동에 따라 제공될 수 있는 학습공지 등을 미리 설계하여 과정 운영상 발생하는 교수자의 부담을 경감하였다. 인터페이스 및 학습절차 구성에서 확인된 몇 가지 점 들이 개선되는 것을 고려할 때 본 연구는 효과적인 이러닝 설계를 위한 대안적 시도라는 점에서 의의가 있다.

중심어 : | IMS Learning Design | e-PBL | 이러닝 | 학습활동 |

\section{Abstract}

The purpose of this study is to develop an e-PBL prototype using IMS Learning Design(IMS LD). The e-PBL prototype using IMS LD included 1) developing learning contents and learning activities together, 2) designing learning contents and learning activities which are appropriated to learning outcome and students' roles, and 3) designing the expected notification supporting learners' activity and lessening the engagement of instructors in a process of $\mathrm{e}^{-\mathrm{PBL}}$. The implications of this prototype are to expand the boundary of $\mathrm{e}^{-}$learning design for contents-oriented design to activity-oriented design and to suggest the possibility of adaptive and collaborative e-learning.

keyword : | IMS Learning Design | e-PBL | e-learning | Learning Activity |

\section{I. 서 론}

교육의 패러다임이 교수(instruction) 중심에서 학습 (learning) 중심으로 변화하면서, 이러닝 설계 역시 효
과적으로 콘텐츠를 전달하는 것에서 학습자의 학습활 동을 촉진하는 방향으로 변화하고 있다. 이러한 변화는 학습자가 자신의 환경과 상호작용함으로써 혹은 활동 을 통하여 지식을 구성한다는 구성주의적 교육관에 기

* 본 연구는 2010년도 지식경제 기술혁신사업의 지원을 받아 수행되었습니다(과제번호:10030076).

접수번호 : \#120202-010

심사완료일 : 2012년 02월 20일

접수일자 : 2012년 02월 02일

교신저자 : 홍성연, e-mail : hsy06@ajou.ac.kr 
초한다. 학생들이 주어진 문제에 대한 해결안을 찾기 위해 협동학습과 개별학습을 반복해 나가는 문제기반 학습(Problem-based learning, 이하 PBL)은 대표적인 구성주의 학습 환경 설계 모형이다. 의학지식만으로 해 결하기 어려운 의료현장의 실제적인 문제를 의과대학 생들에게 효과적으로 교육하기 위한 방법으로 고안된 $\mathrm{PBL}$ 은 학습대상과 내용을 막론하고 여러 교육현장에 서 대표적인 학습자 중심 학습 환경 설계 모형으로 활 용되고 있다.

그러나 다양한 학습 환경과 빈번한 상호작용을 필요 로 하는 PBL을 면대면 교육환경에서 실행하기에는 시 간, 공간은 물론 물적-인적 자원 등 여러 제약이 따른다 [1][2]. 이러한 제약을 해소하기 위하여 온라인상에서 $\mathrm{PBL}$ 을 구현하는 e-PBL에 대한 시도와 연구가 1990년 대 중반부터 진행되어 왔다[2][3].

e-PBL은 웹이 지니고 있는 매체의 잠재력을 활용하 여 $\mathrm{PBL}$ 이 요구하는 학습자 중심적 학습 환경을 구축함 으로써 학생들 간의 효과적인 상호작용과 풍부한 학습 자원 제공을 가능하게 한다[4]. 따라서 e-PBL의 설계에 서 주의할 점은 학습자들이 PBL에서 요구하는 다양한 학습활동을 온라인 상에서 진행할 수 있도록 구성주의 적인 학습 환경을 설계하는 것이다.

그러나 대다수의 이러닝 프로그램이 학습내용을 전 달하는 것에 치중하고 있는 상황에서 학습자들이 다양 한 학습 활동을 할 수 있는 온라인 환경을 구성하는 것 은 쉬운 일이 아니다. 학습자의 다양한 학습 활동을 유 도하기 위해서는 교수자-학습자, 학습자-학습자 간의 상호작용이 활발하게 이루어져야 하는데, 이를 유도하 기 위해서는 수업 운영 전반에서 교수자 혹은 튜터의 적극적인 개입이 요구되기 때문이다. 이것은 다시 이러 닝 프로그램 운영 비용의 증가라는 현실적인 문제에 부 딪치게 된다.

이러한 한계로 인하여 현재까지 이러닝 프로그램은 효과적으로 구조화된 교수설계에 기초한 콘텐츠 중심 프로그램을 대상으로 학습자가 독립적으로 학습할 수 있도록 구성된 것이 대부분이었다. 상대적으로 e-PBL 과 같이 대인 상호작용이 높은 프로그램은 적극적인 상 호작용과 학습자 및 교육환경에 따른 융통성 있는 수업 운영이 요구되기 때문에 대학의 이러닝 수업이나 고비
용의 전문 이러닝 프로그램에서만 제한적으로 운영되 어 왔다. 또한, 구조화 정도가 낮은 $\mathrm{e}-\mathrm{PBL}$ 의 경우, 현실 적으로 교수자가 내용전문가, 교수설계자, 튜터의 일인 삼역을 담당함으로써[2] 교수자의 역량과 노력에 따라 $\mathrm{e}-\mathrm{PBL}$ 의 질이 결정되는 경우가 대부분이었다. $\mathrm{PBL}$ 자 체가 교수자들의 수업부담이 높은 교수학습모형으로 인식[1]되고 있는 상황에서 $\mathrm{e}-\mathrm{PBL}$ 과 같이 학습자와 대 면하지 않고 테크놀로지를 활용해 융통성 있게 학습 환 경을 구성해 나가야 한다는 것은 교수자의 부담을 더욱 가중시키는 일이다. 교수자들의 부담감과 그에 따른 소 요비용 때문에, e-PBL은 교육적으로 효과적인 교수학 습모형임에도 불구하고 이러닝에서 적극적으로 활용되 지 못하였다.

그러나 최근 이러닝을 학습활동 중심으로 개발하려 는 시도가 이루어지면서 e-PBL 설계의 새로운 가능성 이 제시되고 있다. Instructional Management Systems Global Learning Consortium(IMS GLC)은 이러닝 환경 에서 학습활동을 중심으로 이러닝 프로그램을 설계, 개 발할 수 있도록 안내하는 구조틀이자 언어인 IMS Learning Design(IMS LD)을 발표하였다[5]. IMS LD 에 기반한 이러닝 프로그램은 다양한 상황들을 고려한 학습설계를 가능하게 한다. 예컨대, 학습자 각자의 역할 과 수준에 따라 서로 다른 학습활동을 수행하도록 학습 기능과 인터페이스를 조정할 수 있으며, 토론, 공지 등 의 학습지원 기능을 적절한 시기에 자동으로 제공함으 로써 학습자가 그에 맞는 활동을 하도록 유도할 수 있 다. 또한 학습자의 상황과 역할에 따른 학습운영 및 지 원이 프로그램 설계 단계에서 논의됨으로써 $\mathrm{e}-\mathrm{PBL}$ 의 운영에서 나타나는 교수자의 부담감과 비용 문제를 해 결하게 해준다.

이에 본 연구는 IMS LD에 기반하여 e-PBL 프로그 램의 프로토타입을 개발함으로써 $\mathrm{e}-\mathrm{PBL}$ 의 실제적 가 능성을 검토해 보고자 한다. 이를 위해 IMS LD을 기반 으로 하는 학습활동의 개념과 설계 원리를 살펴보고, 해당 설계원리[6]에 기초한 e-PBL 프로토타입을 개발 한 후 개선 방안을 제시하였다. 본 연구의 연구문제는 다음과 같다.

1. IMS LD 기반 e-PBL 프로토타입의 형태는 어떠한 가? 
2. IMS LD 기반 e-PBL 프로토타입의 개선 방향은 무엇인가?

\section{II. 이론적 배경}

1. e-PBL

\subsection{PBL의 특성}

최근 문제해결력이 현대인에게 요구되는 핵심역량으 로 부각되면서 이를 위한 학습 환경 설계 모형인 $\mathrm{PBL}$ 역시 주목받고 있다. PBL에 대한 선행연구를 살펴보면 학습자의 학습을 촉진하는 것은 물론, 문제해결력에 미 치는 효과가 유의미한 것으로 나타났다[7].

$\mathrm{PBL}$ 의 특징은 크게 여섯 가지로 정리할 수 있다 [1][2][7][8]. 첫째, 비구조화된 문제가 학습의 출발점이 자 구심력이 된다. 둘째, 학습자는 교과목보다 비구조화 된 문제를 분석하고 해결하는 과정에서 통합적으로 지 식을 구성한다. 셋째, 모든 학습은 학습자 중심으로 이 루어진다. 넷째, 교수자는 모델링과 코칭을 통해 학습자 의 문제해결을 지원하는 촉진자로서 역할을 한다. 다섯 째, 학습은 다른 학습자와의 다양한 상호작용을 통해 협력적으로 이루어진다. 여섯째, 성찰이 중요한 학습과 정으로 이루어진다.

\subsection{PBL 적용의 제한점}

$\mathrm{PBL}$ 의 교육적 효과에도 불구하고, 실제 교육현장에 서 $\mathrm{PBL}$ 를 적용하는 것은 쉽지 않다. 무엇보다 교수자 가 교수설계자, 튜터, 내용전문가의 여러 역할을 효과적 으로 수행하는 것에 대한 부담이 크다. 교수자 입장에 서 느끼는 $\mathrm{PBL}$ 적용의 제한점을 살펴보면 다음과 같다 [1][8].

첫째, 교수자의 PBL에 대한 이해가 부족하며, PBL에 적합한 문제를 개발하는데 많은 노력이 요구된다. 둘째, 교수자가 PBL 수업을 운영하는 과정에서 많은 시간과 노력이 든다. 수업을 설계하고, 자료를 준비하고, 적절 한 피드백을 제공하는데 전통적 방식의 수업에 비해 상 당한 노력과 기술이 요구된다. 셋째, 안내자로서 교사의 역할을 수행하는 것이 쉽지 않다. 효과적인 $\mathrm{PBL}$ 을 위 해서는 교수자가 학습의 조력자이자 촉진자로서 협력
적인 학습문화를 촉진해야 하지만, 이러한 모든 활동을 하기가 쉽지 않다. 넷째, 수업시간의 분배와 평가방법의 선정이 쉽지 않다. 정해진 수업시간 내에 학생 간 토론 을 진행하거나 학습 양을 분배하는데 노하우가 필요하 며, 학생들의 학습과정과 결과를 함께 평가하기 위한 방법을 구현하기가 쉽지 않다.

\section{3 e-PBL의 선행 연구}

테크놀로지를 활용하여 학습자 및 교수자와의 다양 한 상호작용 환경을 구축함으로써 $\mathrm{PBL}$ 수업에서 나타 나는 시간적·공간적 제약을 극복하려는 시도가 1990년 대 중반부터 시작되었다[2][3].

장정아[2]는 학습자들의 상호작용과 교수자의 인지 적 코칭이 온라인상에서 이루어지면 학습의 과정이 면 대면 PBL에 비해 더 효과적으로 구조화될 수 있다고 지적하였다. 온라인상에서 체계적으로 학습자가 문제 를 해결하기 위한 개별학습과 협동학습을 하도록 유도 하기 위해서 교수자가 적절한 시간에 문제와 관련된 자 료를 제시하고, 학습과정을 평가하고, 피드백을 제공하 는 것이 중요하다. 또한, 다양한 학습 자료와 상호작용 이 이루어질 수 있도록 학습 환경을 구축할 필요가 있 다. 따라서 e-PBL을 구축하고 운영하는 과정에서 내용 전문가, 튜터, 교수설계자로서 교수자의 역할이 매우 중 요하며, 많은 시간과 노력이 요구된다.

최근까지 개발된 다양한 $\mathrm{e}-\mathrm{PBL}$ 은 기존의 이러닝과 같이 LMS에서 필요에 따라 조별토론형 게시판과 학습 자료 게시판을 활발하게 활용한 것이 대부분이며, 문제 제시, 문제해결을 위한 자료 제공, 수업진행에 대한 안 내, 질문답변, 팀원 구성, 토론유도, 학습참여도 확인 및 피드백 제공, 평가 등이 모두 교수자에 의해 이루어졌 다. 또한, e-PBL을 위해 개발된 시스템들은 자료의 분 류 및 제시, 팀구성 등에서 교수자의 수고를 덜어주기 위한 것이 대부분이었다. 여전히 개발에 소요되는 많은 비용과 운영 시 교수자의 과중한 역할이 e-PBL의 확산 을 저해하는 요소라 할 수 있다.

\section{IMS LD에 기반한 활동중심 이러닝 설계}

\section{$1.1 \mathrm{IMS} \mathrm{LD}$ 의 개념과 구조}

$\mathrm{IMS} \mathrm{LD}$ 는 학습자가 다양한 상황이나 지식을 학습하 
는 데 활용할 수 있는 이러닝 프로그램과 지원체제의 설계와 개발을 지원하는 구체화된 구조틀이자 개발언 어이다[5]. 기존의 SCORM 기반 이러닝 프로그램이 학 습내용을 중심으로 설계·개발되는 것과 다르게 IMS $\mathrm{LD}$ 기반 이러닝 프로그램은 학습자의 활동을 기준으로 구성된다. IMS $\mathrm{LD}$ 는 하나 이상의 역할별 활동 (role-parts)이 포함된 일련의 막(act)으로 구성된 연극 (play)의 형식을 보이고 있다. 따라서 일련의 조건에 따 라 학습자의 역할별 활동을 설계하게 된다. 즉, $\mathrm{IMS} \mathrm{LD}$ 는 학습내용뿐만 아니라 학습자의 학습활동을 뒷받침 하는 도구, 자원 및 지원 등을 설계 영역에 포함한다 [6][9].

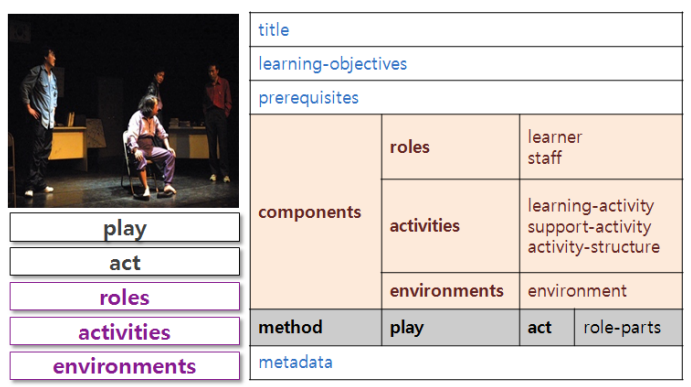

그림 1. IMS LD 표준의 주요 구성요소의 구조

IMS LD 표준(IMS LD specification)에서 학습설계 와 관련된 주요 구성요소들을 살펴보면[그림 1], 학습설 계는 크게 제목(title), 학습목표(learning-objectives), 선수학습(prerequisites), 컴포넌트(components), 메소 드(methods), 그리고 제작연도, 제작자, 내용, 키워드 등 의 메타데이터(metadata)로 구성된다. 이 중 컴포넌트 와 메소드가 학습설계의 핵심이다. 컴포넌트의 학습자 (learner)와 조력자(staff)는 기본적인 역할(roles)에 따 라 학습활동(learning-activity)과 지원활동(support-activity) 으로 이루어진 활동(activities)을 수행한다. 이 때, 활동 은 '활동구조(activity-structure)로 구조화될 수 있혼동 구조동영상 플레이어구조s)을 등 기술지원은 물론 보 충자료구조심화학습 등 학습 자료와 학습 동구로 구성 된 환경(environment)의 지원을 받는다.

메소드는 프로그램의 구조와 함께 컴포넌트에 포함 되는 역할, 학습활동, 그리고 환경의 구성 및 절차를 나
타내는 요소이다. 메소드는 기본적으로 연극(play)과 극에 속하는 막(act), 그리고 실제 연극을 수행하는 역 할과 활동을 연결시키는 역할별 활동(role-parts)로 구 성된다. 여기에서 연극과 막은 이러닝 프로그램과 주차 의 구성을 나타내는 요소이고, 역할별 활동은 컴포넌트 의 요소인 역할, 활동, 그리고 활동에 따른 환경을 학습 설계에 따라 계열화하는 요소이다[5].

이와 함께 역할, 역할별 활동, 활동 결과, 그리고 학습 자와 조력자의 특징 등을 속성(property)으로 연결하여 서 특정한 행동에 상응하는 반응을 조건(condition)으 로 설정할 수 있다. 예컨대, '학습자가 X와 같은 학습양 식을 가지고 있을 때, 무작위 순으로 활동들을 제시한 다'는 것은 학습자가 $\mathrm{X}$ 라는 속성을 가지는 조건을 만족 하면, 해당 교과나 수업에서 자유롭게 자료들을 돌아다 니며 활동할 수 있도록 설계하는 것을 의미한다.

또한, 활동 결과가 특정한 상황에 부합되면 설계된 내용을 알리는 공지(notification)를 활용할 수 있다. 예 컨대, 학습자가 정해진 시간까지 해당 학습활동을 수행 하지 않은 경우에 학습자에게 학습을 독촉하는 공지가 자동으로 발송되도록 설계할 수 있다. 이러한 공지 기 능은 학습자뿐만 아니라 교수자, 조교 등의 조력자에게 도 활용할 수 있다.

\section{$1.2 \mathrm{IMS}$ LD를 활용한 이러닝 설계}

$\mathrm{IMS} \mathrm{LD}$ 기반의 이러닝 설계와 관련된 연구는 아직 활발하게 이루어지지 않았다[10][11]. Westera 외[12]는 IMS LD 기반 이러닝 프로그램의 개발단계를 1) 과목 설계, 2) 프로토타입 개발, 3) 자료 및 시나리오 개발, 4) 수정 및 정교화, 5) 프로그램 테스트 서버 탑재, 6) 프로 그램 실제 서버 탑재, 7) 프로그램 운영 준비, 8) 프로그 램 운영의 여덟 단계로 제안하였다. Sloep, Hummel와 Manderveld[13]는 어떻게 IMS LD 기반의 이러닝 프로 그램을 개발할 것인가에 초점을 두고 1) 역할별 활동 서술, 2) 환경 서술, 3) 활동의 완료 표시, 4) 속성 설정, 5) 공지 설정, 6) 동기점 확인, 7) 활동의 종료 결정, 8) 활동구조 만들기, 9) 컴포넌트 서술, 10) 메소드 서술, 11) 제목, 학습목표, 사전지식, 메타데이터 설정, 12) 자 원 설정 둔 개발 절차를 12 단계로 제안하였다.

임철일 외[6]는 기존의 IMS LD를 활용한 이러닝 설 
계 연구[12][13]가 대부분 IMS LD 표준 구성요소의 설 계 순서를 나열함으로써 개발의 관점에 국한되어 있다 고 지적하고, 학습의 설계 측면에서 $\mathrm{IMS} \mathrm{LD}$ 기반의 이 러닝 설계를 수행할 필요가 있다고 주장하였다. 해당 연구에서는 미시적 교수설계 측면에서 1) 시나리오 개 발, 2) 순서도 개발, 3) 스토리보드 개발, 4) 패키징 안내 서 개발의 네 단계를 제시하고, 문헌분석에 기초하여 $\mathrm{IMS} \mathrm{LD}$ 에 기반한 이러닝 설계원리를 다음과 같이 여 덟 가지로 제시하였다.

- 학습내용과 학습활동이 통합적으로 이루어질 수 있도록 설계하라.

· 학습자의 사전지식에 적응적으로 설계하라.

- 역할에 적합한 학습내용, 학습활동 및 지원활동을 설계하라.

- 각각의 '학습활동' 및 '지원활동'은 주요활동과 보 조활동으로 구분하여 설계하라.

- 학습내용, 학습활동 및 화면 구성을 고려하여 각 '학습활동' 및 '지원활동'의 단위를 설정하라.

- 재사용성 및 재생산성을 고려하여 설계하라.

· 학습설계 시 예상되는 공지 및 지원 내용을 '공지' 로 미리 설계하라.

- 해당 수업의 형태를 고려하여, 차시 구성을 설계하 라.

그리고 해당 설계원리가 적용한 스토리보드를 활용 하여 교육공학을 전공하는 9 명의 대학원생을 대상으로 설계원리에 대한 면담 및 설문을 실시하고, 이를 통하 여 설계원리의 강점과 약점, 개선점을 도출하여 분석 · 정리하였다.

\section{III. 연구방법}

\section{1. 연구절차}

IMS LD에 기반한 $\mathrm{e}-\mathrm{PBL}$ 을 개발하기 위하여 [그림 2]와 같은 네 단계를 거쳤다.

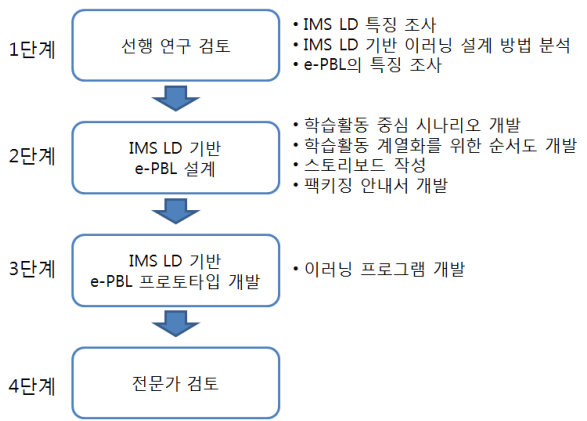

그림 2. 연구절차

첫째, IMS LD 표준, 특성, 이를 기반한 이러닝 설계 방법에 대한 다양한 선행연구 검토가 이루어졌다. 또한, $\mathrm{e}-\mathrm{PBL}$ 에 대한 다양한 선행연구 검토도 같이 이루어졌 다.

둘째, IMS LD 기반 e-PBL 설계가 이루어졌다. 설계 과정은 IMS LD 기반 설계원리[6]에 따라 시나리오, 순 서도, 스토리보드, 팩키징 안내서를 개발하는 순서로 이 루어졌다. 기존에 개발된 '요구분석'에 대한 시뮬레이션 [14]의 교육내용과 자원을 참조하여 학습자들의 활동을 중심으로 전체 교육과정의 시나리오를 개발하였다. 본 개발과정은 교육공학 박사 1 인과 박사과정 1 인의 협업 으로 이루어졌으며, 다른 교육공학박사 1 인의 검토를 거쳤다. 시나리오를 토대로 학습자 및 조력자의 역할별 활동을 도출하고, 학습 전체의 활동 흐름을 보여주는 순서도를 개발하였다. 특정 학습목표에 도달하기 위하 여 수행해야 하는 각 역할별 학습자의 학습활동과 조력 자의 지원 활동 등을 순서도 형식으로 개발하였다. $\mathrm{e}-\mathrm{PBL}$ 의 경우, 팀장, 서기, 자료관리자 등의 학습자 역 할에 따른 각기 다른 학습활동이 주어질 수 있다. 그 다 음으로 이러닝 프로그램을 개발하는데 활용할 스토리 보드를 개발하였다. 프로그램 개발이 완료된 후 모습, 즉 화면의 구성, 화면 단위의 내용 제시 분량과 위치, 메 뉴의 내용과 제시 위치, 진행방법, 상호작용 방법과 주 요 활동이 무엇이며 누가 하는지 등 활동에 대한 설명, 활동을 지원하는 환경, 속성, 조건, 공지 등 구체적인 설 계안을 스토리보드로 작성하였다. 마지막으로 팩키징 안내서는 순서도에 제시된 학습 순서에 따라 기술적 차 원에서 스토리보드를 어떻게 팩키징 하는가를 안내하 
는 설계도면이라고 할 수 있다.

셋째, 개발 단계에서는 설계 단계에서 개발된 중간산 출물 중에서 스토리보드와 팩키징 안내서를 바탕으로 이러닝 프로그램을 개발하였다. 먼저, 스토리보드에 따 라 html 문서 개발하고, 팩키징 안내서를 참고하여 개 별적인 문서들 간의 순서, 연결 관계, 포함 관계, 조건 등을 프로그래밍하여 하나의 프로그램으로 만드는 팩 키징 작업을 수행하였다. 그리고 개발된 이러닝 프로그 램에 대하여 설계자가 검토하고, 이를 반영하여 개발자 가 프로그램을 수정하는 작업을 수행하였다.

마지막으로, 개발된 IMS LD 기반 e-PBL 프로토타 입에 대한 전문가 검토를 수행함으로써 개선점을 도출 하였다.

\section{2. 연구대상}

$\mathrm{e}^{-\mathrm{PBL}}$ 프로토타입에 대한 개선방향을 도출하기 위 한 전문가 검토는 박사과정 2 인을 대상으로 수행되었 다. 이들은 기존의 $\mathrm{e}-\mathrm{PBL}$ 관련 개발과정에 참여한 경 험이 있었으며, $\mathrm{IMS} \mathrm{LD}$ 와 관련된 기초지식을 가지고 있었다. 따라서 교육공학의 관점에서 $\mathrm{IMS} \mathrm{LD}$ 기반 $\mathrm{e}-\mathrm{PBL}$ 프로토타입에 대한 전문가적인 개선방향을 제 안해 줄 것으로 기대되었다. 전문가 검토는 프로토타입 을 제시하고 자유롭게 학습 및 설계과정에서의 문제점 을 제안하는 형태로 이루어졌다.

\section{III. 연구결과}

본 연구에서 IMS LD 기반 e-PBL은 임철일 외[10]가 제시한 여덟 가지 설계원리에 기초하여 설계 및 개발되 었다.

\section{IMS LD기반 e-PBL의 내용 및 구성}

개발된 $\mathrm{e}-\mathrm{PBL}$ 프로그램은 '교육요구분석의 개념, 절 차 및 적용'에 대한 내용으로, 다음 [표 1]은 해당 프로 그램의 내용 및 구성을 나타낸 것이다.
표 1. IMS LD 기반 e-PBL의 내용 및 구성

\begin{tabular}{|c|c|l|}
\hline 주차 & 모듈 & \multicolumn{1}{c|}{ 학습활동 } \\
\hline 1주차 & 1 & PBL에 대한 진단평가 및 학습 \\
\hline \multirow{2}{*}{ 2주차 } & 2 & 팀 구성 확인 및 일정 결정 \\
\cline { 2 - 3 } & 3 & 팀명, 역할 및 규칙 결정 \\
\hline \multirow{2}{*}{ 3주차 } & 4 & 문제 파악 및 접근 \\
\cline { 2 - 3 } & 5 & 문제에서 요구하는 학습내용 추론 \\
\hline 4주차 & 6 & 자기주도학습 수행 \\
\hline 5, 6주차 & 7 & 문제의 해결안 작성 \\
\hline 7주차 & 8 & 문제 해결안 요약 및 종합 정리 \\
\hline
\end{tabular}

본 프로그램은 7 주의 온라인 학습으로 이루어지며, 총 여덟 개의 모듈로 구성되었다. IMS LD 기반 이러닝 설계 원리 중 '해당 수업의 형태를 고려하여 차시 구성 을 설계하라'를 적용하여, 모듈 2에서 모듈 8은 PBL 모 형의 학습형태를 고려하여 설계되었다. 전체 학습이 온 라인으로만 이루어지기 때문에 학습자들이 학습방법인 $\mathrm{PBL}$ 에 대해 얼마나 알고 있는지 확인하기 어려운 점을 고려하여, 모듈 1 에서 $\mathrm{PBL}$ 에 대한 진단평가를 실시하 여 학습자의 선수지식 수준을 확인하고, 그 결과에 따 라 선택적으로 $\mathrm{PBL}$ 에 대한 지식을 보충할 수 있도록 설계하였다.

\section{IMS LD 기반 e-PBL 프로토타입}

\section{1 기본 화면 구성}

IMS LD 기반 e-PBL 프로토타입의 기본 화면은 다 음 [그림 3]과 같다. [그림 3]은 모듈 1 의 'PBL에 대한 진단평가 및 학습' 중에서 하나의 학습활동에 대한 전 체 화면을 나타낸 것이다.

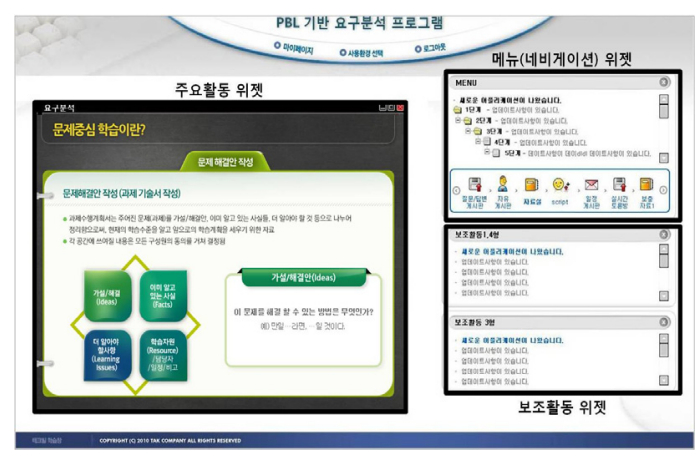

그림 3. IMS LD 기반 e-PBL 프로그램의 전체 화면 
해당 이러닝 프로그램은 웹 기반의 위젯으로 개발되 었다. 웹 브라우저 안에 컴퓨터 바탕화면과 같이 '프로 그램 바탕화면'이 있고, 그 안에 창 형태의 위젯이 여러 개 떠 있는 방식이다. 기본적으로 프로그램 바탕화면에 는 주요활동을 수행하는 '주요활동 위젯'과 주요활동에 따른 보조활동을 나타내는 '보조활동 위젯', 그리고 주 요활동과 보조활동을 제어하는 '메뉴 위젯'이 뜨도록 구 성하였다. 학습자가 메뉴에서 트리 형태의 학습활동을 선택하게 되면 해당 내용이 주요활동 위젯에 나타남과 동시에 그에 따른 아이콘 형태의 보조활동 메뉴가 동적 으로 제시되도록 설계, 개발하였다.

여러 개의 위젯이 학습 절차와 학습자의 편이에 따라 이동될 수 있도록 설계, 개발함으로써, 학습자는 수동적 으로 이러닝 콘텐츠를 보면서 학습하는 것이 아니라 $\mathrm{e}-\mathrm{PBL}$ 프로그램 내에서 상황에 따라 유동적으로 변화 할 수 있는 동적인 학습활동과 자원들을 활용하여 적극 적으로 학습에 참여하도록 유도하였다. 이 때, 한 화면 에서 적절한 학습이 이루어질 수 있도록 주요활동 위젯 과 보조활동 위젯에 포함될 학습내용과 학습활동의 종 류를 결정하였다. 또한, 인터페이스 측면에서도 일반적 으로 컴퓨터를 활용하여 윈도우의 바탕화면에서 여러 개의 프로그램을 실행하는 것처럼 느낄 수 있도록 하였 다. 이러한 구성은 한 화면에서 학습자가 학습활동을 수행하면서 동시에 학습에 필요한 보조자료 및 도구들 을 활용할 수 있게 지원함으로써 학습 몰입을 높이고 활동 중심으로 이러닝을 구성할 수 있도록 유도한다.

또한, 각각의 위젯들은 $\mathrm{PBL}$ 의 절차에서 문제 해결을 지원하는 자료들이 중복적으로 사용되는 상황을 고려 하여, 학습자의 활동에 따라서 주요활동이나 보조활동 위젯으로 재사용될 수 있도록 구성하였다. [그림 3]의 주요활동은 이후 모듈 6 인 '자기주도학습 수행'에서 보 조활동으로 다시 사용되어야 하므로, 프로그램과 주차 의 제목을 주요활동 내에 포함시키지 않았다.

이와 같이 기본 화면을 구성하면서 '각각의 '학습활 동' 및 '지원활동'은 주요활동과 보조활동으로 구분하여 설계하라', '학습내용, 학습활동 및 화면 구성을 고려하 여 각 '학습활동' 및 '지원활동'의 단위를 설정하라', '재 사용성 및 재생산성을 고려하여 설계하라'는 IMS LD 기반 이러닝 설계원리가 반영되었다.

\section{2 통합적인 학습 환경}

효과적인 학습을 위해서는 학습내용을 습득하는 과 정과 학습활동이 통합적으로 이루어질 필요가 있다. IMS LD 기반 이러닝 설계원리의 '학습내용과 학습활 동이 통합적으로 이루어질 수 있도록 설계하라'는 학습 자들이 학습활동을 수행하면서 학습내용을 따로 불러 오거나 게시판 등 다른 지원 도구를 별도로 사용하지 않고, 통합적으로 학습할 수 있음을 의미한다. [그림 4] 는 모듈 3인 ‘팀명, 역할 및 규칙 결정' 중에서 한 팀에 속하는 네 명의 학습자가 모여 팀명과 팀 역할을 결정 하는 학습활동을 나타낸 것이다.

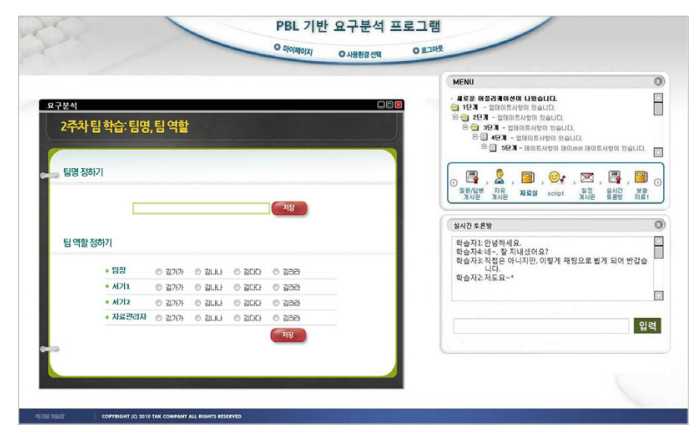

그림 4. 모듈 3 중 '팀명, 팀 역할 결정' 의 전체 화면

IMS LD 기반 e-PBL에서는 일반적인 e-PBL과 달리 별도의 메신저나 게시판을 사용하지 않고, 학습흐름에 맞게 설계된 주요활동과 보조활동을 하나의 학습화면 에 설계함으로써 통합적으로 학습활동을 수행할 수 있 다. [그림 4]는 학습흐름에 따라 보조활동 위젯에 나타 난 실시간 토론방을 활용하여 팀명과 팀 역할을 정하 고, 그 결과를 주요활동 위젯에 기록한 것이다. 주요활 동 위젯에 기록된 토론결과는 IMS LD의 '속성 (property)'에 저장되어, 이후의 학습활동에 활용될 수 있다. 이와 같이 IMS LD 기반의 e-PBL은 기존의 $\mathrm{PBL}$ 과 e-PBL과는 달리 통합적인 학습 환경을 제공함으로 써, 학습자가 일관된 맥락 안에서 학습활동을 수행할 수 있도록 설계되었다.

\section{3 진단평가 결과에 따른 적응적 학습}

'학습자의 사전지식에 적응적으로 설계하라'는 설계 
원리에 따르면, 학습자의 진단평가나 학업성취도의 수 준에 따라 서로 다른 학습활동을 하도록 설계할 수 있 다. 다음 그림은 모듈 1 인 'PBL에 대한 진단평가 및 학 습’ 중 $\mathrm{PBL}$ 에 대한 진단평가 결과를 확인하는 학습활 동의 주요활동 위젯을 제시한 것이다.

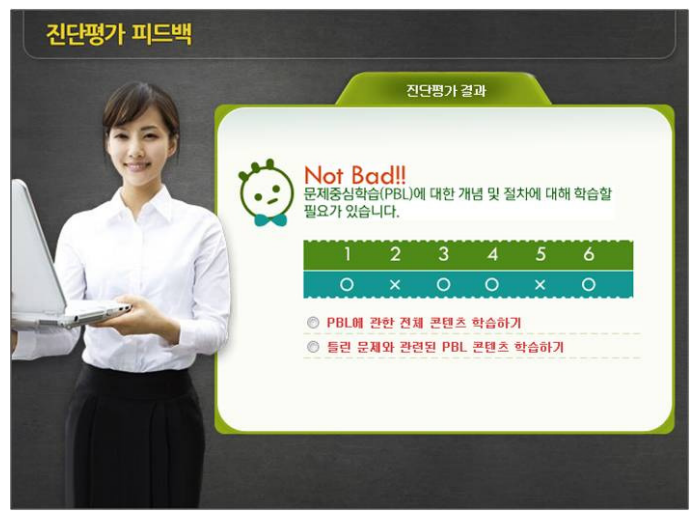

그림 5. 모듈 1 중 '진단평가 결과' 의 주요활동 위젯

본 프로그램에서 $\mathrm{PBL}$ 진단평가는 총 여섯 개의 문항 이며, 각 문항은 $\mathrm{PBL}$ 의 개념 및 특징, 절차, 문제해결안 작성, 자기주도적 학습, 평가에 대한 내용으로 구성되어 있다. [그림 5]에 제시된 바와 같이 학습자는 진단평가 결과에 따라 $\mathrm{PBL}$ 에 대한 전체 내용을 학습할지, 아니 면 자신이 틀린 문제와 관련된 내용만 학습할지 선택할 수 있다. 틀린 문제와 관련된 내용만 학습하고자 했을 때, 각 학습자에 따라 선별적으로 학습내용이 제시된다. 이를 통하여 학습자는 PBL에 대한 학습 수준을 확인하 고, 부족한 부분을 미리 학습함으로써 이후 모듈 2 부터 진행되는 PBL 절차에 따라 원활하게 학습할 수 있다.

\section{4 역할에 따른 학습활동 제시}

$\mathrm{IMS} \mathrm{LD}$ 기반 이러닝 설계원리의 '역할에 적합한 학 습내용, 학습활동 및 지원활동을 설계하라'는 연극에서 배우에 따라 역할이 다르듯 학습자의 역할에 따라 다른 학습내용, 학습활동, 지원을 제공하는 것으로 IMS LD 의 특징을 잘 드러낸다. 다음은 모듈 5 인 '문제에서 요 구하는 학습내용 추론'의 '적용 및 반추하기' 중에서 이 후 개별학습을 위하여 ‘학습자원을 선택'하는 활동의 주 요활동 위젯을 나타낸 것이다.
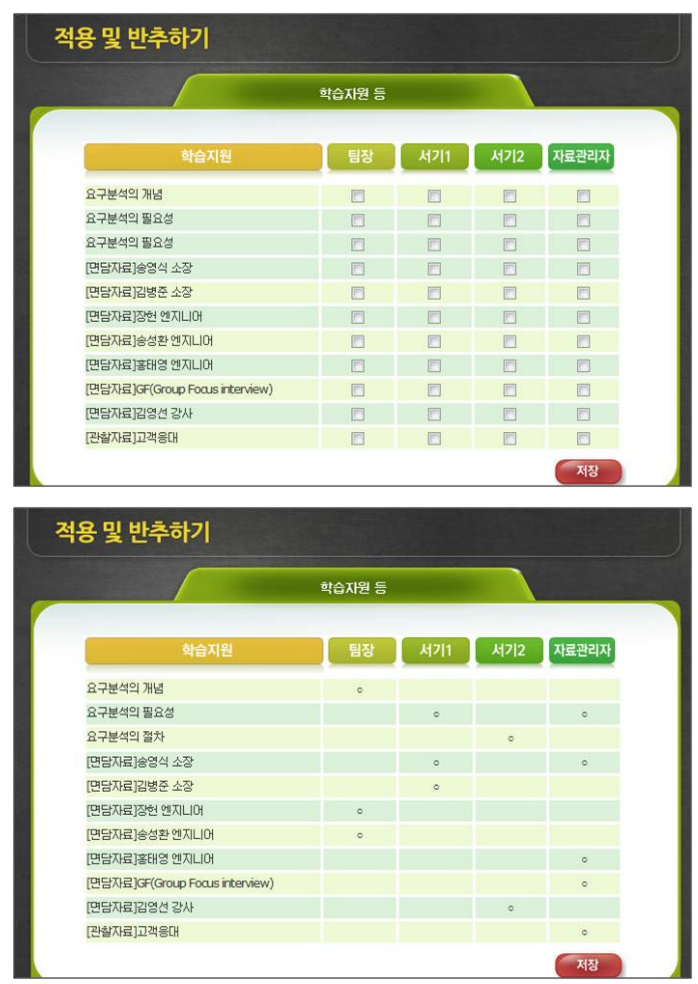

그림 6. 모듈 5 중 '학습자원 결정' 의 주요활동 위젯

위의 학습활동에서 네 명의 팀 구성원은 [그림 4]와 같이 보조활동 중 하나로 제공되는 실시간 토론방을 활 용하여 누가, 어떤 자원을 활용하여 학습할지 토론, 결 정한다. 그 결과는 서기 1 혹은 서기 2 에게만 제시되는 [그림 6]의 상단 활동을 통하여 기록되고, 그 외 학습자 들은 [그림 6]의 하단 활동을 통하여 서기 1 혹은 서기 2 가 기록한 내용을 확인할 수 있다. 즉, 학습자들이 스스 로 어떤 학습내용과 활동을 할지 토론을 통해 결정하 면, 그에 따라 해당 학습자에게 적절한 학습내용과 지 원이 제공되는 것이다. 이 설계원리는 PBL과 같이 팀 학습이 이루어지고, 팀별로 역할과 그에 따른 학습활동 이 설계되어야 하는 학습모형을 이러닝 환경에 효과적 으로 구현하는 데 중요한 원리라 할 수 있다.

\section{5 학습상황에 따른 공지}

$\mathrm{IMS} \mathrm{LD}$ 는 특정 속성에 해당하는 학습자에게 학습내 용 및 활동, 피드백, 공지 등을 수신할 수 있다. 교수자 
가 특정 속성에 해당하는 학습자를 쉽게 검색할 수 있 으며, 학습 시작 전에 학습자가 특정 학습활동을 수행 하면 관련된 피드백이나 공지 등을 자동으로 수신하도 록 연계할 수 있다. 이는 IMS LD 기반 이러닝 설계원 리의 '학습설계 시 예상되는 공지 및 지원 내용을 '공지' 로 미리 설계하라'와 관련된다. [그림 7]은 학습자에게 이메일을 통하여 자동적으로 전달되는 공지를 제시한 것이다.

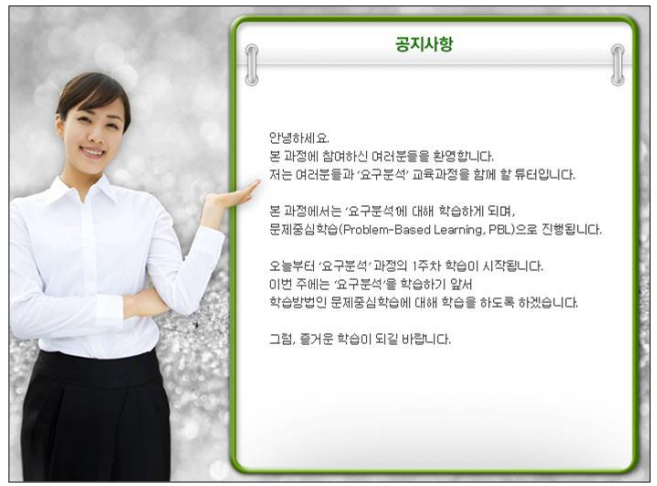

그림 7. 1 주차 특정 시간과 상황에 전달되는 공지

위의 [그림 7]에서의 공지는 첫 번째 주의 여섯 째날 오전 8시까지 모듈 1을 모두 학습하지 않은 학습자들에 게만 선별적으로 이메일을 통하여 전달되게 된다. 이는 $\mathrm{e}-\mathrm{PBL}$ 을 설계, 개발할 때에 예상되는 상황과 공지를 미리 설계하여 운영 시에 자동적으로 공지를 제공하는 IMS LD의 '공지(notification)' 기능을 활용한 것으로, 기존의 PBL과 e-PBL에서 튜터가 프로그램을 운영하 면서 필요할 때마다 일일이 수동으로 공지하는 것에 비 하여 효과적이다.

\section{IMS LD기반 e-PBL 프로토타입의 개선방향}

IMS LD 기반 e-PBL 프로토타입에 대한 전문가 검 토를 수행한 결과, 크게 네 가지 문제점이 도출되었으 며, 각 문제점에 대한 개선방향이 논의되었다.

첫째, 한 화면에 주요활동 위젯과 보조활동 위젯이 함께 제시되는 것이 학습의 편리성과 역동성 측면에서 는 효과적일 수 있으나, 컴퓨터 해상도에 따라 오히려 불편할 수도 있다. 따라서 주요활동 위젯과 보조활동
위젯의 크기를 임의적으로 변형하거나 선택적으로 사 용하도록 수정할 필요가 있다.

둘째, 학습내용과 학습활동을 통합적으로 제시하는 것은 학습의 흐름이 끊어지지 않고 집중할 수 있게 하 며, 보다 역동적인 이러닝 학습활동을 가능하도록 하는 강점을 가지고 있다. 하지만 학습내용과 학습활동이 섞 여 있기 때문에, 이후에 학습한 내용을 정리할 때에 번 거로울 수 있다는 점이 약점으로 지적되었다. 그러므로 학습내용만을 별도로 제공하여, 학습자가 학습 후에 이 를 정리할 수 있도록 지원할 필요가 있다.

셋째, 학습과정에서 필요한 공지 및 지원 내용을 미 리 설계하여 제공하는 것은 관리자나 교수자가 $\mathrm{e}-\mathrm{PBL}$ 을 운영할 때 수동으로 공지하는 번거로움을 줄여주기 는 하지만, 학습자가 자동 공지를 형식적으로 생각할 우려가 있다. 그러므로 이메일을 통해 전달되는 그림 파일이 아닌 SMS와 같은 문자 서비스를 사용하거나, 완성된 공지가 아닌 일부 설계된 공지 템플릿을 운영 시 간단한 작업을 통해 완성하는 방법 등을 활용하여 미리 설계된 공지로 느끼는 정도를 감소시킬 필요가 있다. 마지막으로 설계된 주차에 맞춰 모듈이 제시되도록 e-PBL의 내용과 구성을 개발하게 되면, 학습자가 학습 진도를 통제할 수 있는 범위가 줄어들기 때문에 효과적 인 학습활동을 수행할 수 없다는 점이 지적되었다. 특 히, $\mathrm{PBL}$ 과 같이 팀 학습이 많은 부분을 차지하는 학습 모형을 설계할 때에는 다수의 학습자가 활동하는 팀 학 습의 특성을 고려하여, 학습 진도와 일정을 좀 더 유동 적이고, 자율적으로 설정할 수 있도록 프로토타입을 수 정할 필요가 있다.

\section{V. 결론 및 제언}

e-PBL의 교육적 효과에도 불구하고 학습활동 중심 의 이러닝의 개발 및 운영이 쉽지 않기 때문에 대부분 의 e-PBL은 기존의 학습내용 중심의 이러닝과 큰 차이 가 없거나 교수자의 역량과 노력에 따라 큰 수준 차이 를 보였다. 본 연구는 $\mathrm{IMS} \mathrm{LD}$ 를 적용하여 학습활동 중 심의 $\mathrm{e}-\mathrm{PBL}$ 의 개발 가능성을 살펴보기 위하여 IMS $\mathrm{LD}$ 기반 e-PBL 프로토타입을 개발하고 그 개선방향을 
제시하였다.

IMS LD 기반 e-PBL 프로토타입이 기존 학습내용 중심의 이러닝과의 차별점은 다음의 네 가지이다.

첫째, 학습내용과 학습활동을 통합적으로 제시하도 록 인터페이스 및 학습과정이 설계되었다. 즉, 내용 중 심의 이러닝에서는 토론이나 의견제시 등 학습자의 활 동은 부수적인 학습활동으로 취급되는 경우가 많았다. 하지만 IMS LD 기반 $\mathrm{e}-\mathrm{PBL}$ 의 경우, 학습자의 활동이 적극적으로 학습 절차에 포함되어 있으며, 인터페이스 가 활동 중심으로 구성되어 있기 때문에 보다 적극적인 학습자의 참여를 기대할 수 있다.

둘째, 진단평가 결과와 같이 학습자 수준에 적합한 학습내용이 제시될 수 있도록 구성되었다. 학습자들의 적성, 학업성취도, 선수학습지식 등 수집될 수 있는 다 양한 학습자 정보에 따라서 학습자 간 서로 다른 학습 내용을 제시하는 것이 가능하기 때문에 보다 적응적인 이러닝을 개발할 수 있다.

셋째, 협동학습에서 각 학습자가 맡은 역할에 따라 서로 다른 학습활동이 제시될 수 있도록 구성되었다. 학습내용과 마찬가지로 학습활동 역시 데이터베이스에 축적된 다양한 학습자 정보에 따라 다른 학습활동을 제 공할 수 있다. 따라서 학습자들은 이러닝 활동에 수동 적인 것이 아니라, 자신에게 주어진 학습활동에 보다 능동적으로 참여할 수 있다.

넷째, 학습자의 활동 정도에 따라 제공될 수 있는 학 습공지를 미리 설계하여 과정 운영 시 교수자의 부담을 줄일 수 있도록 설계되었다. 활동 중심 이러닝의 경우 학습과정 중에 교수자의 개입이나 점검이 많이 요구되 기 때문에 상대적으로 교수자의 부담이 크다. 학습절차 나 개별학습자의 학습진행 정도에 따라 학습자들에게 보내야 하는 공지들을 미리 설계해 놓음으로써 과정 운 영 시에는 교수자의 부담을 최소화할 수 있다.

개선방향에서 지적되었듯이 IMS LD 기반 e-PBL 프 로토타입은 학습의 편리성과 역동성을 높여주기는 하 지만, 지원 과정에서 일부 인터페이스 및 학습활동이 수정될 필요가 있다. 특히, 시나리오, 순서도, 스토리보 드, 팩키징 안내서 등 기존과 다른 이러닝 개발과정이 교수설계자 및 이러닝 개발자들에게 익숙하지 않을 수 있다. 그러나 이러닝에서 발생할 수 있는 다양한 학습
자들의 학습활동들을 모듈화하고 교수자가 선택한 학 습모형에 따라 필요한 모듈을 선택적으로 활용하여 학 습활동 중심의 이러닝을 구성하였을 때, 개발상의 어려 움은 줄어들 것으로 보인다.

IMS LD 기반 e-PBL은 학습내용 전달 위주의 이러 닝을 학습자의 활동 중심으로 변화시킬 수 있는 효과적 인 시도라고 할 수 있다. 기존의 학습관리시스템을 활 용하는 경우에는 학습내용과 학습활동이 별도로 운영 되지만, IMS LD를 활용하면 학습 흐름에 따라 학습내 용과 학습활동이 통합된 형태로 제시된다. 예컨대, 기존 의 학습관리시스템을 활용하는 $\mathrm{e}-\mathrm{PBL}$ 에서는 이러닝 콘텐츠와 토론, 공지와 같은 학습활동의 지원이 각각 이루어지며, 운영 시에 교수자나 학습자가 적절한 시기 에 안내해야 한다. 하지만 IMS LD 기반 e-PBL에서는 $\mathrm{PBL}$ 절차에 따른 학습내용과 학습활동이 함께 제시되 며, 절차에 필요한 학습지원을 사전에 설계하여 자동으 로 제공되도록 한다.

이상과 같이 이러닝의 질적 도약을 위해서는 $\mathrm{PBL}$ 을 비롯한 다양한 활동 중심의 교수학습모형이 이러닝으 로 구현될 필요가 있으며, IMS $\mathrm{LD}$ 는 이러닝 환경에서 적응적 학습과 협동학습 개발을 위한 기술적인 토대를 제공해줄 것으로 기대된다.

\section{참 고 문 헌}

[1] 박성희, "PBL의 대안으로써의 E-PBL : 외국 사 례를 중심으로”, 창의력교육연구, 제 9 권, 제 1 호, pp.113-130, 2009.

[2] 장정아, "온라인 문제기반학습 설계모형 개발 연 구”, 서울대학교 박사학위논문, 2005.

[3] L. Malopinsky, J. R. Kirkley, R. Stein, and T. Duffy, "An instructional design model for online problem based learning environments: The learning to teaching with technology studio," Proceedings of the Association for Educational Communications and Technology, 2000.

[4] 강명희, 허희옥, 최수진, 조일현, 강인애, 임철일, 송상호, $e^{-}$러닝 콘텐츠 설계, 서현사, 2007. 
[5] R. Koper, An introduction to learning design. In R. Koper (Ed.), Learning Design: A Handbook on Modelling and Delivering Networked Education and Training, Springer-Verlag, pp.3-20, 2005.

[6] 임철일, 김선영, 홍성연, “IMS Learning Design' 기반 이러닝 설계원리에 관한 연구", 교육정보미 디어연구, 제16권, 제4호, pp.601-629, 2010.

[7] H. S. Barrows, How to design a problem-based curriculum for the preclinical years, Springer, 1985.

[8] 나지연, "대학수업을 위한 문제중심학습 설계모 형 개발”, 안동대학교 박사학위논문, 2011.

[9] 임철일, 홍성연, 김선영, "이러닝 설계에서 'IMS Learning Design'의 의의와 가능성에 관한 탐색 적 연구", 교육정보미디어연구, 제 15 권, 제 4 호, pp.177-202, 2009.

[10] D. Burgos, P. Moreno-Ger, J. L. Sierra, B. Fern ández-Manjón, M. Specht, and R. Koper, "Building adaptive game-based learning resources: The integration of IMS Learning Design and <e-Adventure>," Simulation Gaming, Vol.39, No.3, pp.414-431, 2008.

[11] E. Sánchez, M. Lama, R. R. Amorim, J. C. Vidal, and A. Novegil, "On the use of an IMS LD ontology for creating and executing Units of Learning: Application to the Astronomy case study," Journal of Interactive Media in Education, Vol.2008, p.21, 2008.

[12] W. Westera, F. Brouns, K. Pannekeet, J. Janssen, and J. Manderveld, "Achieving e-learning with IMS Learning Design Workflow implications at the Open University of the Netherlands," Educational Technology \& Society, Vol.8, No.3, pp.216-225, 2005.

[13] P. Sloep, H. Hummel, and J. Manderveld, "Basic design procedures for e-learning courses," Learning Design: A Handbook on Modelling and Delivering Networked Education and Training, Springer-Verlag, pp.139-160, 2005. [14] 임철일, 연은경, “사례기반 시뮬레이션 설계 원 리에 관한 형성 연구”, 교육공학연구, 제 25 권, 제 2 호, pp.117-149, 2009.

\section{저 자 소 개}

임 철 일(Cheolil Lim)

정회원

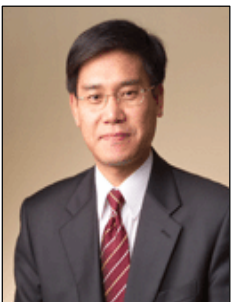

- 1986년 2월 : 서울대학교 교육학 과(교육학사)

- 1988년 2월 : 서울대학교 대학원 교육학과(교육학석사)

- 1994년 7월 : Indiana University 교육공학(철학박사)

- 2004년 3월 현재 : 서울대학교 교육학과 교수 <관심분야> : 창의성 교육, 교수설계, 이러닝, 기업교육

\section{홍 성 연(Seongyoun Hong)}

정회원

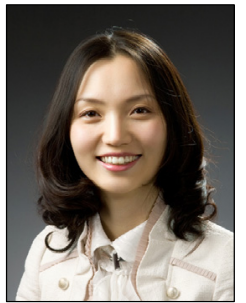

- 1998년 2월 : 연세대학교 사학과 (문학사)

- 2001년 2월 : 서울대학교 대학원 역사교육과(교육학석사)

- 2009년 2월 : 서울대학교 대학원 교육학과(교육학박사)

- 2012년 3월 현재 : 아주대 기초교육대학 대우조교수 <관심분야> : 학습자역량, 교육수월성, 이러닝

\section{김 선 영(Sunyoung Kim)}

정회원

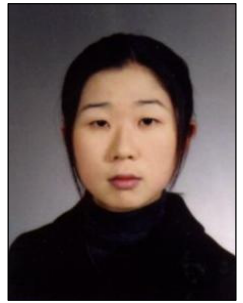

- 2003년 2월 : 서울대학교 컴퓨터 공학부(공학사)

- 2005년 8월 : 서울대학교 대학원 전기 · 컴퓨터공학부 (공학석사) - 2007년 3월 현재 : 서울대학 교 대학원 교육학과 박사과정 <관심분야> : 교수설계, 이러닝, 표준, 전문성 